\title{
MERCURY SELF-POISONING. CASE REPORT
}

\author{
Marieta Yovcheva ${ }^{1}$, Petko Marinov ${ }^{1}$, Snezha Zlateva ${ }^{1}$, Georgi Bonchev ${ }^{2}$, Ivaylo Vazharov ${ }^{3}$ \\ ${ }^{1}$ Clinic for Intensive Treatment of Acute Intoxications and Toxicoallergies, \\ Naval Hospital - Varna, Military Medical Academy \\ ${ }^{2}$ Laboratory of Analytical Toxicology, Naval Hospital - Varna, Military Medical Academy \\ ${ }^{3}$ Clinic of Internal diseases, Naval Hospital - Varna, Military Medical Academy
}

\begin{abstract}
A clinical case of a self-poisoning with a single ingestion of $40-45 \mathrm{~mL}$ of alleged metal mercury with suicidal purpose by a 50-year-old man is described. On the following day he was admitted to the Toxicology Clinic with symptoms of nausea, strong abdominal colic, diarrhea, and feces with macroscopic admixture of mercury drops. At the inspection of the residue of the substance, an unusual black-grey color on its surface was noted. Later, mercurous oxide was proven by chemical analysis. No toxic symptoms of the central nervous system, respiratory system or kidneys were observed. X-rays of the abdomen were performed and tracked dynamically: the first one showed numerous round shadows with metal density along the whole colon, the second - after 5 days - showed reduced number of similar shadows only in the distant colon, and the third Xray on the $9^{\text {th }}$ day was normal. Mercury was discovered in the blood: $0.250 \mu \mathrm{mol} \mathrm{L}^{-1}$ on the fourth day after the ingestion and $0.120 \mu \mathrm{mol} \mathrm{L} \mathrm{L}^{-1}$ - on the tenth day. Some therapeutic problems of acute mercury intoxication of present interest are discussed.
\end{abstract}

Keywords: mercury metal, inorganic mercury compounds, mercurous oxide, ingestion, gastrointestinal syndrome

\section{INTRODUCTION}

Mercury poisoning has been well known for a long time. Mercury is a heavy silvery-white metal, liquid at room temperature. It is a cell and protoplasmic toxicant that binds the sulfhydryl groups of proteins and leads to protein precipitation, damage of the cell membranes, reduction of RNA in the cells and blockage of a number of important enzyme systems (1-5). It is toxic in all forms: metal mercury, inorganic and organic mercury compounds (2,5-7). The sourc-

Address for correspondence:

Georgi Bonchev

Naval Hospital - Varna

Military Medical Academy, Bulgaria

$3 \mathrm{Hr}$. Smirnenski St

Varna 9010

e-mail: toxilab.varna@abv.bg

Received: April 6, 2017

Accepted: May 3, 2017 es of poisoning, toxicokinetics and biological effects vary significantly depending on these forms; therefore, the mercury toxicity is also highly varied $(2,3,7-$ $10)$. The main factors for this variety are chemical form, route of exposure (ingestion, inhalation and dermal), duration of exposure (acute or chronic), and the dose and intensity of the exposure $(2,10)$. Metal mercury is dangerous mainly through inhalation, while its ingestion is considered relatively safe $(4,10$ 12). In toxicological literature the opinion that metal mercury is not absorbed by the gastrointestinal tract with intact membranes and has insignificant absorption - less than $0.1 \%$ of the ingested amount - prevails. Some cases of ingestion of significant amounts of metal mercury with suicidal purpose - from 204 $\mathrm{g}$ to $3.0 \mathrm{~kg}(220 \mathrm{~mL})$ without substantial toxic effects - have been described $(5,6,9,11,13-15)$. The authors emphasize on the importance of the normal peristalsis of the bowels and the intact intestinal membranes $(10,16)$. Inorganic mercury compounds are mercu- 
Marieta Yovcheva, Petko Marinov, Snezha Zlateva et al.

rous salts (monovalent) and mercuric salts (bivalent). They enter the blood circulation only by ingestion. They are lipid insoluble, have various degrees of water solubility and do not pass through the hematoencephalic barrier. At first, the soluble mercuric salts are absorbed moderately (7-15\%) and a significant part of $\mathrm{Hg}^{2+}$ can stay unabsorbed, attached to the alimentary mucosa or in the intestinal content, waiting for absorption later. Mercurous salts are not soluble at first, have restricted absorption, but they can undergo oxidation to soluble compounds $(2,7,10)$. Inorganic mercury compounds have an irritating-corrosive effect on the mucosa of the gastro-intestinal tract and especially on the intestines. After the absorption, they accumulate mainly in the liver and kidneys. In the early phase, the mercury in the blood is about $1-1.5 \%$ of the ingested dose. Over $90 \%$ of the inorganic mercury in the blood is bound to the erythrocytes and proteins and less than $1 \%$ is unbound. Its volume of distribution is approximately $20 \mathrm{~L} / \mathrm{kg}^{-1}$. It is eliminated mainly via the kidneys by glomerular filtration and tubular secretion and also via biliary excretion, with the feces. The third form, organic mercury compounds, is highly liposoluble, pass through the hematoencephalic barrier and cause a severe cerebral toxic syndrome $(5,9,17,18)$. Organic mercury compounds are not a subject of this article, but their impact on human health continues to be an international problem $(4,5,9,13,17-20)$.

We describe a clinical case of a single-time ingestion of a significant amount of initially reported pure metal mercury, about $40-45 \mathrm{ml}$, with suicidal purpose, by a 50 -year-old man who was in good health before that. The diagnosis was formed on the basis of the history, clinical toxic syndrome, the residue of the substance in the vial, the toxicology laboratory results and X-ray images.

\section{MATERIALS AND METHODS}

Hospital case 4256/2016. Macroscopic inspection and classical wet chemistry semi-micro qualitative analysis of the residue of the substance found at the bottom of the brought vial in the Laboratory of Analytical Toxicology in Naval Hospital - Varna were conducted. Quantitative toxicological chemical analysis of the patient's blood for mercury was done at the Analytical Laboratory in St. Ivan Rilsky Hos- pital, Sofia. Native X-ray of the abdomen were performed on 31.08.2016, 04.09.2016 and 07.09.2016.

\section{RESULTS}

\section{Anamnesis}

R.Y.M., a man, 50 years old, from the village of G., Varna District, was admitted to the Toxicology Clinic on 31.08.2016 with a history of strong abdominal cramps, nausea and diarrhea with admixture of blood which started about 24 hours after a single ingestion of alleged metal mercury, with suicidal purpose. The patient said that the mercury had been taken many years ago from a nowadays non-existing department of the Polyvinylchloride Production Plant in the town of Devnya and was kept in a well-sealed $50 \mathrm{~mL}$ glass vial. Before the intoxication, the patient was in good health. Physical examination: conscious, oriented, tense, with dysthymia. No ataxia, convulsions or negative neurological symptoms, normal muscle tonus. There were normal color and turgor of the skin and oral mucosa. The respiratory rate was 24 per minute. The examination also showed: vesicular breathing, no wheezing; bradycardia $45 / \mathrm{min}$, rhythmic; later $65 / \mathrm{min}$. The arterial blood pressure was normal. The abdomen was soft with painful palpation in the lower abdominal half, along the colon. There were no symptoms of peritoneal irritation; no organomegaly and non-painful renal succussion.

\section{Diagnostics}

Macroscopic inspection of the original vial (Fig. 1) has shown approximately $1 \mathrm{~mL}$ of liquid, visibly non-clean mercury (Fig. 2). Several milligrams of fine black powder were found as a residue in the vial

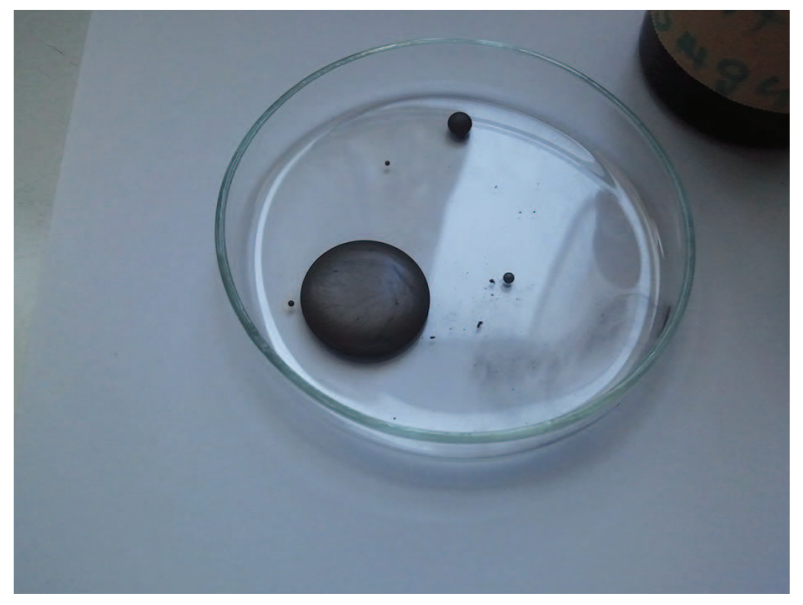

Fig. 1. The original vial 


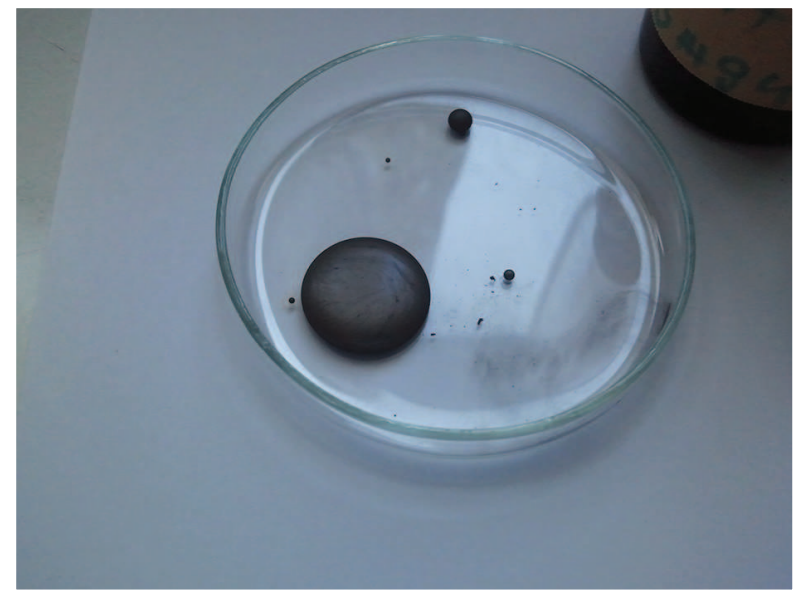

Fig. 2. Liquid mercury leftover

(Fig. 3). Classical wet chemistry semi-micro qualitative analysis has proven mercury (I) oxide as its principal component. Toxicological chemical analysis of blood for mercury was performed: 03.09.2016 ( $4^{\text {th }}$ day after ingestion $)-0.2500 \mu \mathrm{mol} \mathrm{L} \mathrm{L}^{-1} ; 08.09 .2016\left(10^{\text {th }}\right.$ day) $-0.1200 \mu \mathrm{mol} \mathrm{L}^{-1}$. The results were received after the discharge of the patient from the hospital.

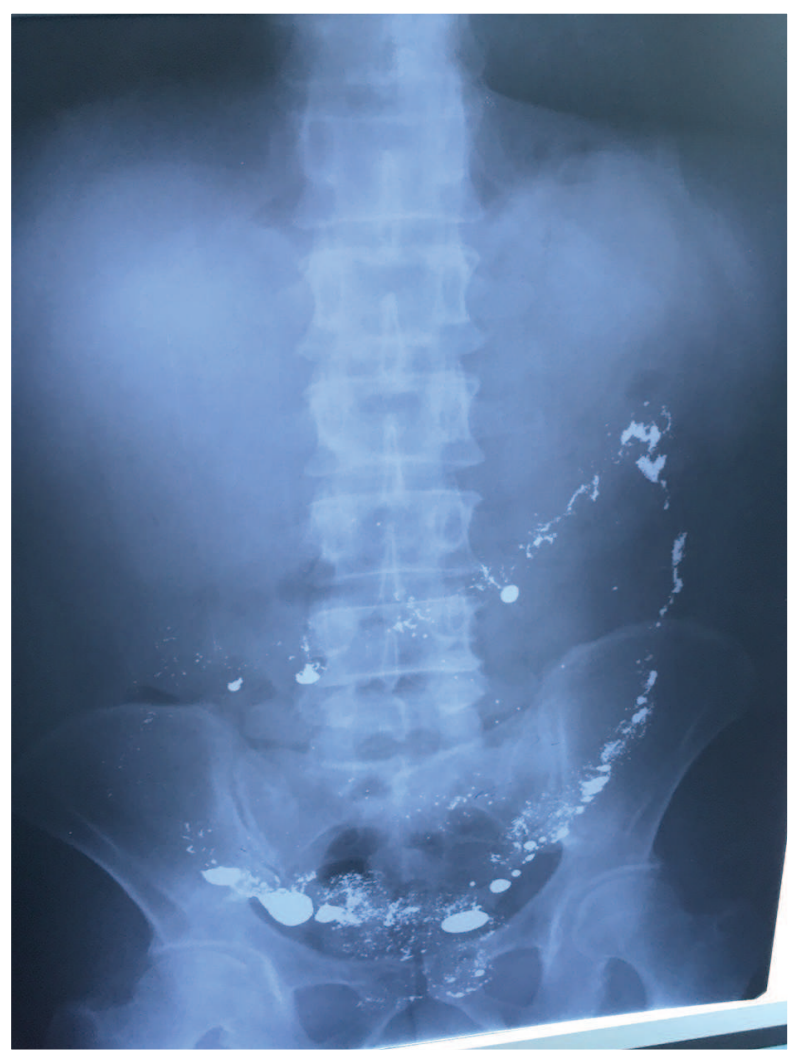

Fig. 4. X-ray on 31.08.2016: numerous X-positive round shadows with metal density along the colon - "mercury necklace"

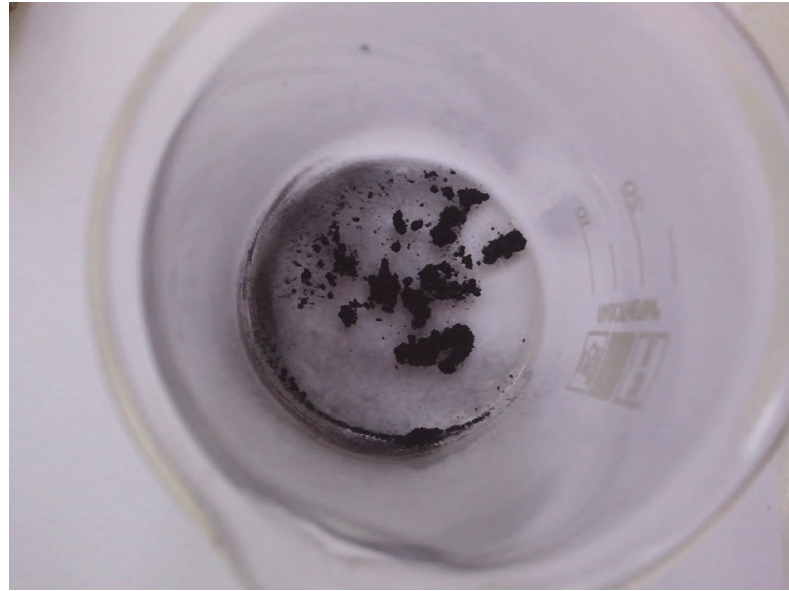

Fig. 3. Black powder found together with mercury in the original bottle

Routine laboratory tests showed results within normal ranges. The ECG data were: on admittance - sinus bradycardia 44/min, indifferent cardiac position. Control ECG-s showed sinus rhythm. The Xray of the lungs and heart was normal. The X-ray of the abdomen showed the following: on 31.08.2016 -

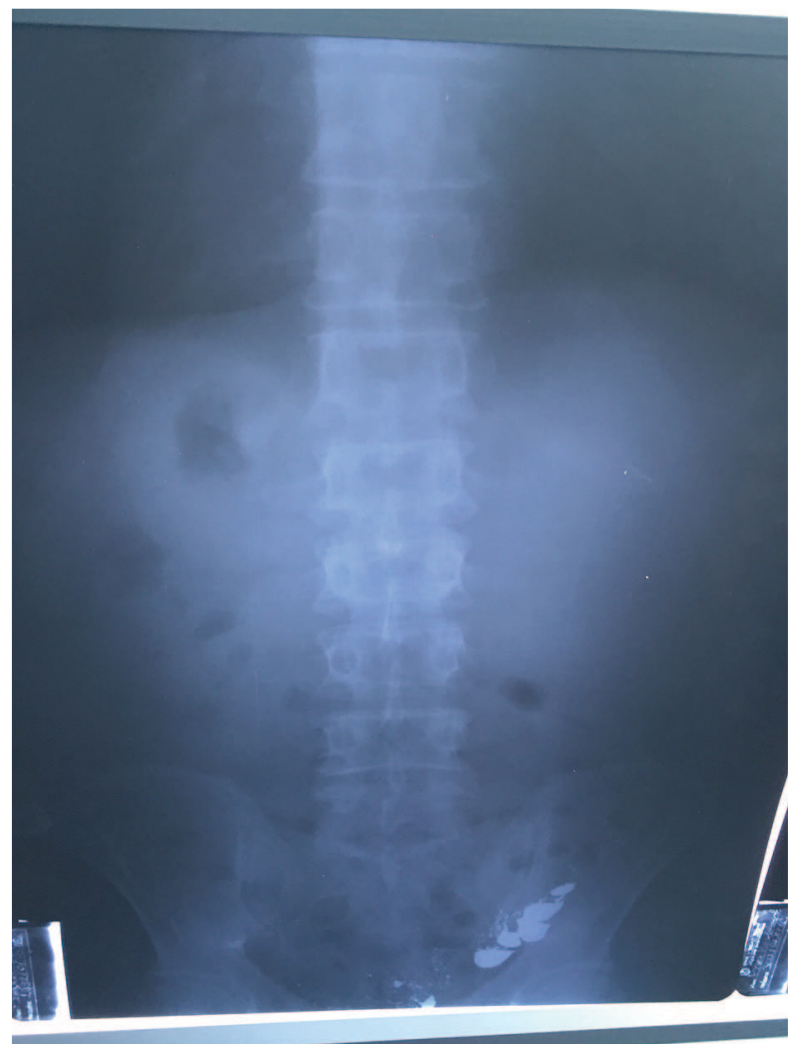

Fig. 5. X-ray on 04.09.2016: reduced number of positive shadows along the descendant colon 
Marieta Yovcheva, Petko Marinov, Snezha Zlateva et al.

numerous X-positive round shadows with metal density along the colon (Fig. 4); on 04.09.2016 - reduced number of similar shadows along the descendant colon (Fig. 5); and on 07.09.2017 - normal image of the abdomen, no pathologic shadows.

The ultrasound diagnostic of the abdomen showed a blurred boundary between renal cortex and pyelonephritis of both kidneys. The ultrasound image of the other abdominal organs was normal. Fibrogastroscopy and fibrocolonoscopy were planned, but refused by the patient. A consultation with a surgeon determined that there were no symptoms of an acute abdominal surgical problem. A consultation with a psychiatrist lead to the diagnosis - disorder of adaptation. There was a protracted depressive reaction and a suicide attempt. The patient was directed to the Psychiatric Department of the St. Marina University Hospital in Varna, but declined to be admitted there.

\section{Treatment}

We have performed stomach lavage, bowel irrigation and used osmotic laxative repeatedly, intravenous infusion of electrolyte and glucous solutions, H2-blocker - Quamatel (famotidin) IV, inhibitor of the proton pump - Ulcoprol (omeprazol), spasmolytics, analgesics, antibiotic - Ceftriaxon IV, and included a diet as well. Antidote treatment was delayed due to deficit of Dimercaprol.

Clinical course: during the first week the patient suffered from constant abdominal pain, mainly cramps along the colon, with temporary effect of spasmolytics. After the $6^{\text {th }}$ day, the intensity of the abdominal symptoms was reduced. Until the 5-6 $6^{\text {th }}$ day, mercury particles could be macroscopically seen in the feces. On the $9^{\text {th }}$ day the patient was better, without cramps or diarrhea and was discharged on his own will, with prescription and dietetic advice. Three days later, he phoned about renewed appearance of abdominal cramps and diarrhea, possibly with blood admixture, without any laxatives. He was admitted to the Gastroenterology Department of another hospital for diagnostic gastroscopy and colonoscopy, but once again refused these procedures and left on his own will. He did not return to the Toxicology Department of the Naval Hospital for re-admittance either and missed all the dates for control examination. Several months later, on the telephone, his relatives declared that he had refused any medical help but was "well".

\section{DISCUSSION}

The described clinical case created several diagnostic and therapeutic problems from the beginning. Although we had a clear history of ingestion of a significant amount of pure metal mercury, confirmed by the X-ray of the abdomen, the clinical presentation with severe gastroenterocolitis and later, the high mercury blood levels found, were in contradiction with the expected lack of absorption, none or minimal local effects and lack of serious toxicity of the ingested metal mercury. It resembled inorganic mercury oral intoxication. When the vial was brought, the macroscopic inspection showed visible residue - fine grayish-black powder. Classical wet chemistry semi-micro qualitative analysis proved mercury (I) oxide as its principal component. According to the literature, the metal mercury may oxidize to mercury oxide in nature when there is moist air, forming a film of $\mathrm{Hg}_{2} \mathrm{O}$, but it is a very slow process (20). Later, the presence of $\mathrm{Hg}_{2} \mathrm{O}$ as impurity in liquid mercury has found its reasonable explanation, as the industrial origin (electrochemical application) of this specific sample has been confirmed. The mercury poisoning in this case was with mixed mercury forms: inorganic compound and metal mercury, with prevailing inorganic mercury toxic syndrome. The mercury blood level was higher than expected. Additional route of exposure - inhalation of metal mercury vapours before the oral ingestion was discussed, but the patient denied such possibility and no central nervous or respiratory toxic symptoms were observed. The following differential diagnoses were discussed: (i) Ingestion of metal mercury, contaminated by inorganic mercury compound/s; (ii) Ingestion of pure metal mercury by a patient with pre-existing disease of the gastrointestinal tract with loss of intact intestinal mucosa; (iii) Combination of metal mercury ingestion and inhalation of mercury vapours and (iv) Combined intoxication by unknown toxin with gastrointestinal disturbing effects and ingestion of metal mercury. Treatment was mainly depuration and symptomatic at first. The existing deficit of antidotes for heavy metal intoxications has delayed antidote treatment. Additional obstacle was created by the negative attitude of the patient to some 
diagnostic and therapeutic procedures. The possible delayed toxic gastrointestinal and kidney symptoms in this case could not be followed and treated properly because of his refusal of control examinations.

\section{CONCLUSION}

Although mercury intoxication, especially with suicidal purpose, is rare in Bulgaria, this case showed that some amounts of industrial mercury can be kept for years and used with significant toxic effects. The mercury poisoning in this case was mixed - with two different mercury forms: inorganic compound $\left(\mathrm{Hg}_{2} \mathrm{O}\right)$ and metal mercury, with leading clinical presentation of $\mathrm{Hg}_{2} \mathrm{O}$ toxic syndrome. Chemical examination played a very important role for the right diagnosis because of the high toxicity of the inorganic compound. The described case was a diagnostic challenge at the admittance of the patient and confirmed the necessity of strict verification of the form of mercury in mercury poisonings, based on the history, clinical toxic syndromes and toxicological chemical analysis.

\section{REFERENCES}

1. Kaloyanova F. Hygiene toxicology. Part II. Sofia: Higiena i fizkultura; 1983. [in Bulgarian]

2. Monov A. Clinical toxicology. Sofia: Medicina i fizkultura; 1981. p. 146-150 [in Bulgarian]

3. Benson B. Heavy metals (Pb, As, Hg). San Francisco: Scribd.; c.2017 [cited 2017 Apr 06]. [Internet]

4. Clarkson TW, Magos L. The toxicology of mercury and its chemical compounds. Crit Rev Toxicol. 2006;36:609-62. doi: 10.1080/10408440600845619

5. Cunha J. Mercury poisoning. Mercury poisoning definition and facts. Portland: MedicineNet; c19962017 [cited 2017 Apr 06]. [Internet]

6. Olson D. Mercury Toxicity. New York: Medscape; c1994-2017 [updated 2016 Dec 12, cited 2017 Apr 06]. [Internet]

7. Park JD, Zheng W. Human exposure and health effects of inorganic and elemental mercury. J Prev Med Public Health. 2012;45(6):344-52. doi: 10.3961/jpmph.2012.45.6.344

8. Lukanov M. Occupational health. 2nd ed. Sofia: Medizina i fizkultura; 1984. p. 217-22 [in Bulgarian].

9. Liu J, Goyer RA, Waalkes MP. Toxic effects of metals. In: Casarett LJ, Doull J, Klaassen CD, editors.
Casarett and Doull's toxicology: the basic science of poisons. 7th ed. New York: McGraw-Hill; 2008. p. 931-979.

10. Seyffart G. Poison index: the treatment of acute intoxication. 4th ed. Lengerich: Pabst Science; 1997. p. $428-440$.

11. Tezer H, Kaya A, Kalkan G, Erkocoglu M, Ozturk K, Buyuktasli M. Mercury poisoning: a diagnostic challenge. Pediatr Emerg Care. 2012 Nov;28(11):1236-7. doi: 10.1097/ PEC.0b013e31827208b0

12. Viccelio P. Handbook of medical toxicology. 1st ed. New York: Little Brown \& Co; 1993. p. 286-288

13. Safety data sheet: Mercury. Karlsruhe: Carl Roth GmbH; 2016 Mar 15. [cited 2017 Apr 06]. [Internet]

14. Deschamps F, Strady C, Deslee G, Menciere-Faroy B, Deschamps S. Five years of follow-up after elemental mercury self-poisoning. Am J Forensic Med Pathol. 2002;23(2):170-2.

15. Triunfante $P$, Soares ME, Santos A, Tavares $S$, Carmo H, Bastos Mde L. Mercury fatal intoxication: two case reports. Forensic Sci Int. 2009;184(1-3):1-6. doi: 10.1016/j.forsciint.2008.10.023

16. Clayton GD, Clayton FE (editors). Patty's industrial hygiene and toxicology: Volume 2A, 2B, 2C: Toxicology. 3rd ed. New York: John Wiley Sons; 19811982. p. 1771

17. Medical management guidelines for mercury. Atlanta: Agency for toxic substances and disease registry (ATSDR). [updated 2014 Oct 21, cited 2017 Apr 06]. [Internet]

18. International Program on Chemical Safety (IPCS). Inorganic mercury: environmental health criteria 118. Geneva: WHO; 1991. [cited 2017 Apr 06]. [Internet]

19. Halbach S, Welzl G. Levels of organic and inorganic mercury in human blood predicted from measurements of total mercury. J Appl Toxicol. 2010 Oct;30(7):674-9. doi: 10.1002/jat.1540

20. Young-Jin S. Mercury. In: Hoffman RS, Howland MA, Lewin NA, Nelson LS, Goldfrank LR, eds. Goldfrank's toxicologic emergencies. 8th ed. New York: The McGraw-Hill Companies; 2006. p. 96. 